University of Windsor

Scholarship at UWindsor

1998

\title{
The effectiveness of social work with older people and their families: A meta-analysis of conference proceedings
}

Amanda M. Grenier

McMaster University

Kevin M. Gorey

University of Windsor

Follow this and additional works at: https://scholar.uwindsor.ca/socialworkpub

Part of the Social Work Commons

\section{Recommended Citation}

Grenier, Amanda M. and Gorey, Kevin M.. (1998). The effectiveness of social work with older people and their families: A meta-analysis of conference proceedings. Social Work Research, 22 (1), 60-64.

https://scholar.uwindsor.ca/socialworkpub/19

This Article is brought to you for free and open access by the School of Social Work at Scholarship at UWindsor. It has been accepted for inclusion in Social Work Publications by an authorized administrator of Scholarship at UWindsor. For more information, please contact scholarship@uwindsor.ca. 
The effectiveness of social work with older people and their families: A met...

Amanda M Grenier; Kevin M Gorey

Social Work Research; Mar 1998; 22, 1; ProQuest Nursing \& Allied Health Source pg. 60

\title{
RESEARCH NOTE
}

\section{The effectiveness of social work with older people and their families: A meta-analysis of conference proceedings}

\author{
Amanda M. Grenier and Kevin M. Gorey
}

A recent meta-analysis of 88 published studies evaluating social work interventions found them to be effective (Gorey, 1996). This research concluded that nearly eight of every 10 clients ( 78 percent) who engaged social work services did better than the typical nonparticipating client. This index of social work's average interventive effect size was estimated to be significant in both a statistical and practical clinical or policy sense. Moreover, Gorey's meta-analysis of the extant social work research literature of the $1990 \mathrm{~s}$ essentially replicated the overall findings of similar reviews from the 1970s and 1980s (Reid \& Hanrahan, 1982; Rubin, 1985; Thomlison, 1984; Videka-Sherman, 1988).

The consistent inference has been that social work services are helpful (that is, that they significantly ameliorate, alleviate, or solve the client- and worker-identified problem) to the vast majority of people who use them. There is a plausible alterna tive explanation for the touted effectiveness of social work, though, and that is that because the meta-inferences of Gorey and others were primarily based on the summarization of published research, it may be that their overall positive findings are solely cxplainable by the tendency for peer-reviewed journals to print "significant" or nonnull findings. This potential "file drawer prob-

Amanda M. Grenier, BSW, is MSW candidate, School of Social Work, McGill University, 3506 University Street, Montreal, Queber, Canada H3A $2 A 7$. Kevin M. Gorey, is associate professor, Social Work Program, University of Windsor, Windsor, Ontario, Canada. lem" (Rosenthal, 1979), or publication bias, has not yet been adequately accounted for in reviews of the research on the effectiveness of social work practice. The present meta-analysis of conceptually similar, although unpublished, social work research findings will do so. Also, by focusing on gerontological practice, it will integratively review a field of social work that has not previously been so summarized.

We are aware of only one study on the potential potency of publication bias among the social work research literature (de Smidt \& Gorey, 1997). In fact, de Smidt and Gorey's meta-analysis of unpublished graduate student research (dissertations and theses) suggested that publication bias could probably be rejected as a salient alternative explanation for social work's observed effectiveness. However, although direct evidence is not available on this score, one may conjecture that some (and perhaps many) of the student authors who formed their "unpublished" sampling frame, particularly those hoping to become academics, may already have been experiencing "publish or perish" pres sure. If so, there may be a greater tendency among them to report "significant" results that may be more "publishable" later, during their early academic careers, in peer-reviewed journals. The meta-analysis reported in this article sought to empirically clarify this question by systematically replicating a recent review of published research on the effectiveness of social work (Gorey, 1996) and a similar review of dissertations and theses (de Smidt \& Gorey, 1997) using another source of unpublished research, conference proceedings.

\section{METHOD}

Recent (1990 to 1996) conference presentations from the annual scientific meetings of the 
Gerontological Society of America (GSA) that reported empirical findings on the effectiveness of gerontological social work (work with older people and their families) were this review's sampling frame. This largest of the field's annual professional conferences accepted manuscript abstracts at a rate of 88 percent in 1996; none were disqualified simply on the basis of nonsignificant findings, and acceptance rates for the years 1990 to 1995 were reported to be similar to the 1996 rate (personal communication with S. E. Gordon, GSA Director of Conferences, July 22, 1996). Forty-two conference proceedings were selected from Volumes 30 (1990) to 36 (1996) of The Gerontologist (see Sample Presentations list following the References). The sample of studies for metaanalysis comprises the abstracts of these presentations. This meta-analysis exactly replicated Gorey's (1996) previous analysis based on published research in its use of the subject key word search scheme and the calculation of a scale-free effect size metric, the $r$ index (interpretable as Pearson's $r$ ), for each study as well as its summarization across the 42 studies (Cooper, 1989; Light \& Pillemer, 1984). Abstracts affiliated with schools of social work or social welfare that met these criteria were included, as well as other multidisciplinary ones in which social workers were involved in theory development or service delivery.

\section{RESULTS}

\section{Sample Description}

The 42 conference proceedings typically ( 86 percent) had samples of fewer than 200 client participants (median $=89$; combined intervention and comparison groups ranged widely from one to 14,000). All except one Canadian study were carried out in the United States. They also all, except one single-system design, used group research de signs to evaluate direct, face-to-face interventions with individuals ( 34 percent), small groups ( 49 percent), or families (17 percent). Study designs included pre- (one group prepost, 42 percent), quasi- (comparison group, 34 percent), and true experiments (randomized control group, 24 percent).

These unpublished studies were similar to their published counterparts (Gorey, 1996) in all of these descriptive characteristics except one. The studies reported at the annual GSA meetings were less likely than their published counterparts to have evaluated organizational or community prac- tice (where the units of analyses were larger than individuals - for example, programs or communities; none versus 27 percent, respectively) $\left[\chi^{2}(1, N\right.$ $=130)=14.16, p<.01]$. This variable was not, however, found to be associated with intervention effect size among the previously reviewed published studies, so by definition (for a third variable to confound a bivariate relationship it must minimally be associated with both of them) it cannot confound this study's unpublished-published effect size comparison.

\section{Effectiveness of Gerontological Social Work Interventions}

In combining the results of the 42 conference proceedings, our review essentially replicated the general effectiveness of social work interventions found by the previous review of published social work research; we found a mean $r$ index of .240 (95 percent confidence interval $[\mathrm{CI}]$ of .163 , .317) (Table 1). Conversion to Cohen's (1988) $U_{3}$-a statistic that compares all of an intervention group's outcome measure scores with a

TABLE 1-The Effectiveness of Social Work Interventions with Older People and Their Families: Conference Proceedings Compared with Published Research

\begin{tabular}{|c|c|c|c|}
\hline \multirow{2}{*}{$\begin{array}{l}\text { Effect Size } \\
\text { Statistic }\end{array}$} & \multirow{2}{*}{$\begin{array}{l}\text { Conference } \\
\text { Proceedings }^{a}\end{array}$} & \multicolumn{2}{|c|}{ Published } \\
\hline & & All & Gerontological $^{b}$ \\
\hline Studies $(n)$ & 42 & 88 & 20 \\
\hline Minimum $r$ & .000 & -.380 & .020 \\
\hline Maximum $r$ & .997 & .962 & .941 \\
\hline Mean $r$ & .240 & .356 & .345 \\
\hline$S D$ & .253 & .261 & .239 \\
\hline$r(95$ percent $\mathrm{CI})$ & $.163, .317$ & $.302, .411$ & $.240, .450$ \\
\hline Cohen's $U_{3}$ & $68.9 \%$ & $77.7 \%$ & $76.9 \%$ \\
\hline
\end{tabular}

NOTE: $\mathrm{CI}=$ confidence interval. Conference proceedings versus all published studies $[t(128)=2.42, p<.05]$ or versus published gerontological studies $[t(60)=1.59, p<.10]$, both one-tailed.

${ }^{2}$ Sample included studies of social work with older people themselves ( 25 studies, 60 percent), with caregivers ( 13 studies, 31 percent), and simultaneously with both (four studies, 9 percent). The majority of the therapeutic interventions with elders and supportive ones with caregivers were based on generalist, systemic, or task-centered frameworks ( 57 percent); the remainder were cognitive or behavioral theory based. Specific interventive methods ranged widely from less formal individual life review or supportive group work to more structured methods such as cognitive-behavioral group work or task-centered case management. Effect size was not found to differ significantly by these client or treatment factors.

bAdapted from Gorey (1996). 
comparison group median score-allows for the inference that about two-thirds ( 69 percent) of the older clients or their caregiving family members who participated in an intervention did better than the average client in a comparison group.

Not surprisingly, this review of conference proceedings produced a somewhat smaller ( 10 percent attenuation) average effect size ( 69 percent) than the one based on all of the published studies (78 percent) or the specifically gerontological ones (77 percent). However, although the overall unpublished-published between-group comparison was statistically significant $(p<.05)$, the meta-analytic comparison of unpublished and published research on the effectiveness of gerontological social work only approached significance $(p<.10)$. Both similarly infer gerontological social work's interventive effectiveness ( 70 percent to 75 percent positive change associated with the intervention); both had $p$ s of less than .05 (combined probability; 95 percent CIs did not include the null). Publication bias does not seem to saliently confound the generally positive inferences of social work effectiveness that have arisen from the profession's peer-reviewed publications.

\section{DISCUSSION}

Recently available unpublished research on social work intervention (1990 to 1996) provides the basis for generally inferring its effectiveness. On the basis of 42 studies presented at the GSA's annual scientific meetings, 69 percent of older clients or their caregivers participating in an intervention do better than the average client in a comparison group. Moreover, this overall finding closely replicates that of a recent meta-analysis of the published research on the effectiveness of social work (Gorey, 1996), as well as another based on unpublished dissertations and theses (de Smidt \& Gorey, 1997).

In a sense, the present article is an extension of these previous ones. Taken together, they demonstrate in a quite unequivocal fashion that publication bias does not potently confound the generally positive inferences about social work's effectiveness that have been reported in peer-reviewed publications. Social workers can be confident in the validity of the notion that their services, and in this instance gerontological social work services, are practically helpful to seven to eight of every 10 clients who use them. This consistent conclusion is not explainable merely by the tendency of social work journals to report positive findings.
Taken together, this series of meta-analyses, which summarize the findings of more than 150 studies on the effectiveness of social work interventions in the $1990 \mathrm{~s}$, converge on the strong inference that such work is helpful for most clients who engage in it. But what of those for whom social work services are ineffective, an estimated two of every 10 social work clients? Answers to questions about their specific needs and the provision of effective services to them ought to be the mission of the next generation of social work research (de Smidt \& Gorey, 1997). Social workers need to extend the population and contextual validity of their professional knowledge base. Having favorably answered the question of social work's overall effectiveness, it is now time to learn how the effects of specific interventions are moderated by specific client, worker, intervention, and other situational characteristics.

\section{Potential Limitation of Conference Proceedings as "Unpublished" Research}

It should be noted that even though studies presented at a conference are clearly categorically definable as unpublished at the time of their presentation, they may subsequently be published in the profession's journals or elsewhere. To the extent to which this review's sample of proceedings has thus penetrated the professional literature, its hypothesized independent variable (unpublished versus published) will misclassify studies. Such misclassification bias does not potently confound this review's central finding for the following reasons. First, at the time of this writing, computer searches of Social Work Abstracts, Psychological Abstracts, Sociological Abstracts, Nursing Abstracts, and Index Medicus revealed that although eight (19 percent) of the conference presentations werc subsequently published (Feather, 1993; Fishback \& Lovett, 1992; Gottesman, Peskin, Kennedy, \& Mossey, 1991; Hebert, Leclerc, Bravo, Girouard, \& Lefrancois, 1994; Kemp, Corgiat, \& Gill, 1992; Rodman, Gantz, Schneider, \& Gallagher-Thompson, 1991; Smith, Tobin, \& Toseland, 1992; Toseland, Labrecque, Goebel, \& Whitney, 1992), support for the criterion validity of this review's unpublished published operational definition remained $\left[r=.86\right.$, converted from $\chi^{2}(1, N=130)=$ $96.29, p<.01$ (34 of 42 unpublished versus none of 88 , Gorey, 1996; $\left(r=\chi^{2} / n\right)^{1 / 2}$, Cooper, 1989)]. Second, exclusion of these eight subsequently published presentations did not result in substantively different meta-analytic inferences. Finally, 
neither did exclusion of the 15 conference presentations from 1995 or 1996 (those most likely to presently be in review or in press). So we are confident that this review validly sampled unpublished social work research.

\section{REFERENCES}

Cohen, J. (1988). Statistical power analysis for the behavioral sciences (2nd ed.). Hillsdale, NJ: Lawrence Erlbaum.

Cooper, H. M. (1989). Integrating research: A guide for literature reviews (2nd ed.). Newbury Park, CA: Sage Publications.

de Smidt, G. A., \& Gorey, K. M. (1997). Unpublished social work research: Systematic replication of a recent meta-analysis of published intervention efficacy research. Social Work Research, 21, 58-62

Feather, J. (1993). Factors in perceived hospital discharge planning effectiveness. Social Work in Health Care, 19(1), 1-14

Fishback, J. B., \& Lovett, S. B. (1992). Treatment of chronic major depression and assessment across treatment and follow-up in an elderly female. Clinical Gerontologist $12,31-40$.

Gorey, K. M. (1996). Social work intervention effectiveness research: Comparison of the findings from internal versus external evaluations. Social Work Research, 20 $119-128$

Gottesman, L. E., Peskin, E., Kennedy, K., \& Mossey, J. (1991). Implications of a mental health intervention for elderly mentally ill residents of residential care facilities. International Journal of Aging and Human Development, 32, 229-245.

Hebert, R., Leclerc, G., Bravo, G., Girouard, D., \& Lefrancois, R. (1994). Efficacy of a support group program for caregivers of demented patients in the community: A randomized controlled trial. Archives of Gerontology and Geriatrics, 18, 1-14.

Kemp, B. J., Corgiat, M., \& Gill, C. (1992). Effects of brief cognitive-behavioral group psychotherapy for older persons with and without disabling illness. Behavior Health, and Aging, 2, 21-28.

Light, R. J., \& Pillemer, D. B. (1984). Summing up: The science of reviewing research. Cambridge, MA: Harvard University Press.

Reid, W. J., \& Hanrahan, P. (1982). Recent evaluations of social work: Grounds for optimism. Social Work, 27 $328-340$.

Rodman, J. L., Gantz, F. E., Schneider, J., \& GallagherThompson, D. (1991). Short term treatment of endogenous depression using cognitive-behavioral therapy and pharmacotherapy. Clinical Gerontologist, $10,81-84$.

Rosenthal, R. (1979). The "file drawer problem" and tolerance for null results. Psychological Bulletin, 86 , $638-641$

Rubin, A. (1985). Practice effectiveness: More grounds for optimism. Social Work, 30, 469-476.

Smith, M. F., Tobin, S. S., \& Toseland, R. W. (1992). Therapeutic processes in professional and peer counseling of family caregivers of frail elderly people Social Work, 37, 345-351.

Thomlison, R. J. (1984). Something works: Evidence from practice effectiveness studies. Social Work, 29, 51-57.
Toseland, R. W., Labrecque. M. S., Goebel. S. T.. \& Whitney, M. H. (1992). An evaluation of a group program for spouses of frail elderly veterans. Gerontologist, 32 $382-390$.

Videka-Sherman, L. (1988). Meta-analysis of research on social work practice in mental health. Social Work, 33 , $325-338$.

\section{SAMPLE PRESENTATIONS}

All abstracts of papers presented at the annual scientific meetings of the Gerontological Society of America are published in The Gerontologist.

Abraham, I. L. (1991). Effects of a cognitive group intervention on cognition, depression, hopelessness and life satisfaction in nursing home residents [Abstract]. Gerontologist, 31, 153

Ambinder, A., Mittelman. M., Mackell, J., Shulman, E.. Steinberg, G., \& Ferris, S. (1990). Relationship between coping strategies and depression in aged caregivers [Abstract]. Gerontologist, 30, 369A.

Beckette, C. D., Haug, M. R., Musil, C. M., Morris. D. L. \& Clapp, M. K. (1995). The effects of social support on anxiety in elderly African-Americans and whites with a chronic illness [Abstract]. Gerontologist, 35. 152.

Caserta, M., Lund, D., Miller, J., \& Feinaeur, L. (1990). The effectiveness of a family counselling program for older adults and their children living in intergenerational households [Abstract]. Gerontologist, 30, 203A

Elliot, L. B., Eggert, G. M., Wamsley, B., \& Teri, L. (1994). Reducing stress and burden for care-givers of Alzheimer's patients using a behaviour management intervention [Abstract]. Gerontologist, 34, 49.

Factor, A.., \& Richter. P. (1991). Evaluating the effectiveness of in-home mental health services to the resistant elderly [Abstract]. Gerontologist, 31, 366.

Feather, J. (1991). Determinants of perceived hospital discharge planning effectiveness [Abstract]. Gerontologist, 31,346

Fishback, J. B., \& Lovett, S. B. (1991). Treatment of chronic major depression, and assessment over treatment and follow-up, in an elderly female [Abstract]. Gerontologist, 31,64 .

Fitzpatrick, T. R. (1992). Stress and well-being among the frail elderly: The effect of social and recreational services [Abstract]. Gerontologist, 32, 55.

Gallagher-Thompson, D., Coon, D., \& Thompson, L. W (1996). Anger expression by type of treatment interaction predicts treatment outcome in family caregivers [Abstract]. Gerontologist, 36, 218

Gottesman, L., Peskin, E., Kennedy, K.. \& Mossey. J. (1990). Implications of a mental health intervention for elderly mentally ill residents of RCFs [Abstract]. Gerontologist, 30, 148A.

Greene, R., Ferrano, E., \& Zarit, S. H. (1995). Caregiver satisfaction with adult day care services for relatives with dementia [Abstract]. Gerontologist, 35, 156.

Gunther, J. S., Taylor, M., Calkins, E., \& Karuza, J. (1996). Outcomes of dynamics system exercise class for older adults with arthritis [Abstract]. Gerontologist, 36, 331

Haight, B. K., \& Michel, Y. (1996). Examining the effects of the life review in nursing home residents over time [Abstract]. Gerontologist, 36, 37.

Hebert, R., Bravo, G., Leclerc, G., Girouard, D.. \& Lefrancois. R. (1992). Efticacy of a support group

The effectiveness of social work with older people and their families: Meta-analysis of conference proceedings / Grenier and Gorey $\mathbf{6 3}$ 
program for caregivers of demented patients: An experimental study [Abstract]. Gerontologist, 32, 267

Ho. P. S., Stegall, M.B.H., \& Wan, T.T.H. (1993). Effects of use of case-managed formal in-home services on the quality of life of the community-based frail elderly [Abstract]. Gerontologist, 33, 299-300.

Holdren, M. E., \& Karuza, J. (1996). Therapy effectiveness and patient satisfaction for older adults served by private practice network [Abstract]. Gerontologist, 36 , 143.

Kaus, C. R., \& Mandel, R. G. (1994). Effects of focused reminiscence on cognition, affect, and social orientation in dementia residents [Abstract]. Gerontologist, 34, 141

Kemp, B. (1990). Brief group cognitive/behavioral therapy for depressed older persons with and without chronic illness [Abstract]. Gerontologist, 30. 97 A.

Kimboko, P. J. (1990). Impact of empowerment interventions on well-being of hard-to-serve elderly [Abstract]. Gerontologist, 30, 172A.

Laliberte, L., \& Mor. V. (1993). Impact of preventive services on health and health practices among the elderly [Abstract]. Gerontologist, 33, 128.

Leach-McMahon, A. (1990). Effects of intervention strategies for adult children caring for elderly parents [Abstract]. Gerontologist, 30, 15A.

Lombardo, N. E.. Berrol, C., Katz, S., \& Ooi, W. L. (1996). Improving mood in frail elders in adult day care and nursing homes through dance/movement therapy [Abstract]. Gerontologist. 36, 40.

Miller, M., Nelson, P., Bullick, P., Sonnier, M., Olson, D., Lynch, J., \& Willenbring, M. (1992). An outpatient clinic approach in case management of the medically ill elderly alcoholic [Abstract]. Gerontologist, 32, 256.

Morrow-Howell, N., Judy, L., \& Becker, S. (1996). Evaluation of an intervention for elders at risk of suicide [Abstract]. Gerontologist, 36, 354

Naleppa, M. J., \& Reid, W. J. (1996). Task-centered case management: Field testing an intervention [Abstract]. Gerontologist, 36, 124-125.

Neuschatz, S.. Shaban. K., Gaines, C., \& Lewis, C. (1996). Interdisciplinary case management: Its effectiveness and efficiency [Abstract]. Gerontologist, 36, 120.

Rodman. J. (1991). Short-term treatment of a complicated bereavement using a combination of cognitivebehavioral psychotherapy and pharmacotherapy [Abstract]. Gerontologist, 31, 95.

Rodman, J., Gantz, F, \& Schneider, J. (1990). Short-term treatment of endogenous depression using a combination of cognitive behavioral therapy for depressed older persons with and without chronic illness [Abstract]. Gerontologist, 30, 97A.

Rubenstein, L. Z., Wieland, S. A., \& Sui, A. L. (1990). Effectiveness of geriatric assessment programs: Metaanalysis of controlled trials [Abstract]. Gerontologist, 30, 181-182A.

Schieberl, J. E. (1995). Support group participation and subjective well-being among caregivers of stroke patients [Abstract]. Gerontologist. 35, 151-152.

Smith, G. C.. Toseland, R. W., \& Tobin, S. (1990). A three month follow-up of peer and professional community for family caregivers [Abstract]. Gerontologist, 30 . $368-369 \mathrm{~A}$

Smith, J., Shua-Haim, J. R., Shua-Haim, V., \& Gross, J. S (1996). The impact of social worker evaluation on length of stay (LOS) in hospitalized elderly: A prospective study [Abstract]. Gerontologist, 36, 119.
Spier, B. E., \& McGrew, J. (1996). Evaluation of the PACE exercise program to improve quality of life of arthritis patients [Abstract]. Gerontologist, 36, 107.

Steffen, A., Futterman, A., \& Gallagher-Thompson, D. (1991). Comparative outcomes of two interventions for caregivers with major depressive disorder [Abstract]. Gerontologist, 31, 369.

Toseland, R., Engelhardt, J., Jue, D., \& Dwyer, P. (1993) Effectiveness of managed care for elderly outpatients [Abstract]. Gerontologist, 33, 299.

Toseland, R., Engelhardt, J., \& O'Donnell J. (1994) Effectiveness and efficiency of GEM care for frail elderly outpatients [Abstract]. Gerontologist, 34, 177178.

Toseland, R., Labrecque, M., \& Goebel, S. (1990). The effectiveness and efficiency of a caregiver support program [Abstract]. Gerontologist. 30, 369A.

Westfried, E. (1995). Group psychotherapy and young older adults: A case study with implications for future cohort groups of older adult women [Abstract]. Gerontologist, 35, 113.

Woods. P., Francis, J., Mcintyre, K., Ashley, J., Ooi, W., Volicer, L., \& Camberg, L. (1996). Family-centered intervention to increase engagement among Alzheimer's patients [Abstract]. Gerontologist, 36,144 .

Wroblewski, H. A. (1990). Healthy lifestyle change attempts of older adults through a holistic approach [Abstract]. Gerontologist, 30, 140A.

Yamada, H. (1992). The effect of emotional social support on the well-being of caregivers [Abstract]. Gerontologist, 32, 267.

Original manuscript received January 22, 1997 Final revision received July 11, 1997 Accepted October 2, 1997

\section{Letters}

Readers: Submit your reactions to and comments about an article published in Social Work Research or a contemporary issue on social work research. Send your letter (three doublespaced pages or fewer) to Letters, Social Work Research, NASW Press, 750 First Street, NE, Suite 700, Washington, DC 20002-4241. 